\title{
Tensile Analysis of Fabric Reinforced Materials
}

RADU BOSOANCĂ, VASILE BRIA, CLAUDIU MEREUȚĂ, ADRIAN CÎRCIUMARU*, IULIAN-GABRIEL BÎRSAN

Research and Development Center for Thermoset Matrix Composites Dunărea de Jos University of Galaț, 47 Domneasca Str.,800008, Galati, Romania

The analysis of reinforced polymers is one of the most important sources of information for materials properties designers. In this regard, due to their intrinsic properties, the fabrics play an essential role when they are used as reinforcement elements. The composites properties can be designed by alternating various types of fabrics, by modifying the orientation of every reinforcement layer, by modifying the matrix properties or by choosing the matrix. This study regards the tensile behavior of four fabric reinforced composites with four different epoxy resins as matrix. All the materials have the same reinforcement structure but the matrix is, in each case, another epoxy resin and more two classes of materials had been studied one is containing the natural polymerized matrix materials and the other one the materials that had been thermally treated according to technical sheet of each polymer. The tests were done one year after the materials formation.

Keywords: carbon, glass and aramide fibers fabrics, epoxy resin, tensile tests

New materials design will always be in development for the industry of aeronautics, automotive, shipbuilding, military and aerospace. The increasingly widespread use of heterogeneous materials, obtained by macroscopically combining two or more homogeneous materials, justifies the interest in finding the most suitable combinations to satisfy certain requirements, as well as in characterizing the behavior of the resulting composite materials [1].

By designing such materials, the combinations of constituents that can achieve the physical and mechanical characteristics necessary for a certain use can be chosen and have, under given operating conditions, a predetermined lifetime. The constituents of a composite material remain separate solid homogeneous phases, but with interfaces that work together $[1,2]$.

Because during the research carried out over a long period of time it was determined that the polymeric composites reinforced with fabrics and epoxy resins showed very good mechanical results [2-5], this paper aims to analyses the behavior of the composite materials reinforced with carbon fibers [6], aramid fibers, glass fibers [7], and homogeneous epoxy matrix. Considering the advantages and disadvantages of chosen fabrics, laminates (pseudo-laminates plates) were formed. These laminates were created with the aim to obtain materials with a low degree of flexibility. Prior to forming these materials, it had been established the type of the polymeric matrix and the types of fabrics which will be used to improve the degree of flexibility [8], the coefficient of thermal expansion [9] and the electrical conductivity [10-12].

For the formation of the materials, bidirectional fabrics with simple netting were chosen, as they provide structural stability [13-15], ensuring mechanical resistance in both directions [16-18] and resistance to delamination [19], presenting considerable advantages. Glass fabrics have high corrosion resistance, good mechanical properties, dielectric properties, lower impact energy absorption capacity compared to aramid fabric and low cost [7,20].

Aramid fibers have a unique combination of high strength, high modulus, tenacity and thermal stability. The non-linear behavior at compression of the aramid fabric fiber, combined with high capacity of deforming under tension, represent an important advantage of its use in applications which requires resistance to severe mechanical stresses. The aramid fabric has excellent impact and fatigue resistance, low thermal expansion, excellent tensile strength, high energy absorption capacity, but is sensitive to UV rays, shows high moisture absorption capacity, low resistance to compression and low adhesion to resins impregnation. Aramid fibers also exhibit fire resistance what is an important property, as the mechanical performance of composites in fire degrades [4].

By using different types of fibers in reinforced composites it is possible to get a material which presents the combination of the advantages of each fibrous constituent and the reduction (to some extent) of the disadvantages [21-24].

During the fabric manufacturing process, the manufacturer uses silane lubricant (silicon hydride) to facilitate processing technology because the fibers are unstable, decreasing the adhesion of the fibers to epoxy resins, and because of this, the fabrics must be treated to remove the lubricant and increasing the adhesion of the fabrics, especially the aramid fabric, to the epoxy impregnation resin, improving the quality of the matrix-fabric interfaces, by dust cleaning, reducing the risk of

*email: acirciumaru@ugal.ro 
causing chemical reactions on the large surfaces of the fabrics. Prior to material formation adhesion tests were done for each pair epoxy resin - fibers fabric and the results showed that all the polymers ensures high quality interface with each of the fabrics.

\section{Experimental part}

\section{Materials and methods}

The mechanical functions of the matrix are to ensure the connection between fibers, to create the rigidity and cohesion of the material and to transmit to the reinforcement the effort exerted on the structure [4, 25-30]. Epoxy resins have superior mechanical and electrical properties compared to other resins and have good chemical and thermal resistance, but having high cross-linking sometimes suffer from brittleness and exhibit low impact properties, which can be improved by fabric reinforcement [31-35]. The use of fabrics also leads to a decrease of the mechanical response of the material because the alternation up-down of the fibers threads in the fabric structure that generates, on one hand, so called polymer pockets (nesting effect) and, on another hand, fibers deformations (undulations) with consequences at the macroscopic behavior of material.

The wet lay-up method of forming is the most suitable when is about forming particular fabric reinforced polymer composites especially when the pot-time of the polymer is long enough to ensure a good penetration of the pre-polymer inbetween the fiber threads. The epoxy resins are generally polymers that in the solid phase are obtained by chemical reactions developed into a mixture of two liquids - the pre-polymer mixture. The brittleness of the polymer is higher when the potlife (gel time) is shorter. Also, in our experience, a short gel time of the pre-polymer mixture does not ensure the necessary quality of the polymer-reinforcement interphase.

The present study was designed to identify the differences between materials with the same reinforcement structure but with different types of epoxy resins as matrix. For the materials forming [8,36-38], the epoxy polymer matrix was chosen, due to the chemical resistance, mechanical strength, high adhesion and dimensional stability, these advantages contributing to the use of epoxy resins for high performance composites.

The four epoxy resins that had been chosen for the study are casting or coating polymers with a gel time longer than 20 minutes. The first epoxy system is Epiphen RE4020 - DE4020 (RE4020 being the so called resin, the main component, and DE4020 being the hardener) [49]. The other three resins are from the same producer, R\&G Gmbh Waldenbuch, and their commercial names are Epoxy Resin C, Epoxy Resin HT2 and Epoxy Resin L [50-52] and as well as the Epiphen system they consist of a main component (resin) and a hardener. Generally the producers are giving information regarding the natural polymerization at room temperature during 14 days but to reach the best quality of the polymer they also recommend thermal treatments. For the formed materials thermal treatment was the same and consists of 90 minutes at $70^{\circ} \mathrm{C}, 60$ minutes at $80^{\circ} \mathrm{C}$ and 30 minutes at $90^{\circ} \mathrm{C}$ after the natural polymerization of polymer matrix of reinforced composites. In order to facilitate the presentation each material will be nominated C, E, H, L with reference to the commercial name of the polymer and, because two classes of materials had been studied (thermally treated and not thermally treated) the thermally treated ones are denoted as CT, ET, HT and LT.

All the four fabrics that had been used as reinforcement elements are of simple type (one step under-above alternation of warp and weft threads) and they are made of carbon fibers threads (C240), aramid and carbon fibers threads (C/A68), aramid fibers threads (A61) and glass fibers threads (G163). The number in parenthesis represents the specific weight of the fabric in $\mathrm{g} / \mathrm{m}^{2}$. The reinforcement is realized as described in table 1. and it is easy to notice that the reinforcement was designed with carbon fiber in the outer layers and glass fibers in the inner layers and each composite is reinforced with 35 sheets of fabrics. The C/A68 fabric is realized by alternating threads of carbon fibers and aramid fibers both on warp and on the weft of the fabric, leading to a balanced material with equals $(50 \%)$ structural contents of aramid and carbon fibers.

The wet lay-up method [4, 39-40] was used ensuring the total impregnation of each reinforcement layer with pre-polymer mixture. The wet lay-up method was used on a modified version that is designed to ensure the material economy, on one hand and the repeatability, on another hand. A seal of EPDM (ethylene-propylene-diene modified) synthetic rubber seal with $D 8 \times 10 \mathrm{~mm}$ profile is realized on a glass plate of $250 \times 340 \mathrm{~mm}$ as it can be observed in fig. 1a. The glass plate is covered with a sheet of polypropylene (because polypropylene is one of the few materials at the epoxy resins do not adhere and facilitates the material extraction after polymerization). The reinforcement layers are placed one after another inside the seal as in fig. 1b. and, at the end, the excess of polymer is removed, another polypropylene sheet is applied and in top of it another glass plate of the same dimensions is placed. In this way a mold is formed and it is left in vertical position for polymerization - fig. 1c. 
Table 1

REINFORCEMENT STRUCTURE

\begin{tabular}{|c|c|c|c|c|c|c|}
\hline \multicolumn{2}{|l|}{ Textile } & \multirow{2}{*}{\multicolumn{5}{|c|}{$\begin{array}{l}\text { Layers orientation } \\
\text { (the cutting angle of the fabric) }\end{array}$}} \\
\hline $\begin{array}{ccc}\text { Fabric } & \text { type } & \text { and } \\
\text { codification }\end{array}$ & Fabric specific weight $\left(\mathrm{g} / \mathrm{m}^{2}\right)$ & & & & & \\
\hline Carbon fibers C240 & 240 & $90^{\circ}$ & $30^{\circ}$ & $45^{\circ}$ & $-30^{\circ}$ & $0^{\circ}$ \\
\hline Mixed fibers C/A68 & 68 & $90^{\circ}$ & $30^{\circ}$ & $45^{\circ}$ & $-30^{\circ}$ & $0^{\circ}$ \\
\hline Aramid fibers A6l & 61 & $90^{\circ}$ & $30^{\circ}$ & $45^{\circ}$ & $-30^{\circ}$ & $0^{\circ}$ \\
\hline Glass fibers G163 & 163 & $90^{\circ}$ & $30^{\circ}$ & $45^{\circ}$ & $-30^{\circ}$ & $0^{\circ}$ \\
\hline Mixed fibers C/A68 & 68 & $90^{\circ}$ & $30^{\circ}$ & $45^{\circ}$ & $-30^{\circ}$ & $0^{\circ}$ \\
\hline Aramid fibers A6l & 61 & $90^{\circ}$ & $30^{\circ}$ & $45^{\circ}$ & $-30^{\circ}$ & $0^{\circ}$ \\
\hline Carbon fibers C240 & 240 & $90^{\circ}$ & $30^{\circ}$ & $45^{\circ}$ & $-30^{\circ}$ & $0^{\circ}$ \\
\hline
\end{tabular}
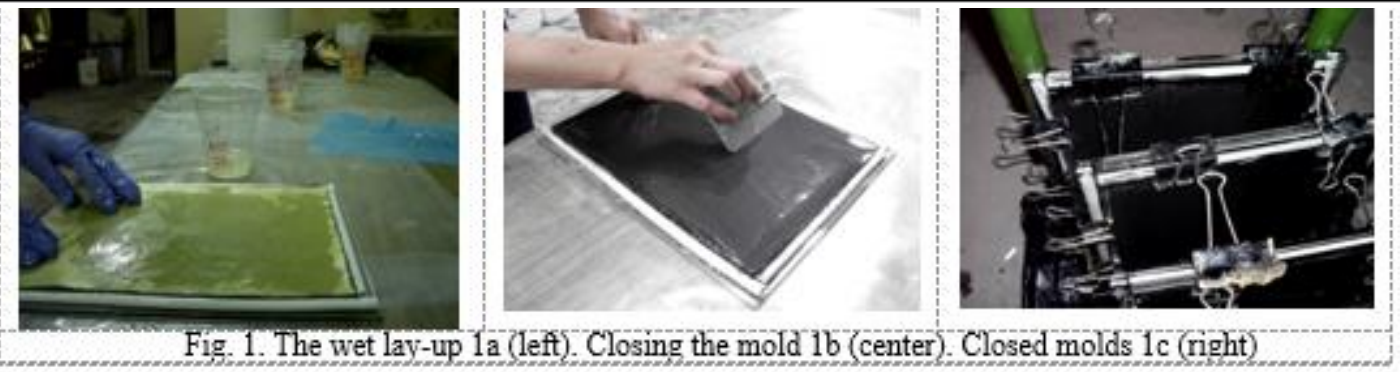

Fig. 1. The wet lay-up 1a (left). Closing the mold lo (center). Closed molds $1 \mathrm{c}$ (right)

The main advantage of laminates is that, based on forming technique, they allow a free distribution of fibers arrangement [41-44]. To meet the objectives of the study, eight laminates with reinforcement and homogeneous matrix were formed. The first aim of the study is to identify the role of the matrix on the tensile behavior of laminates (as long as all of them have the same reinforcement structure) and the second aim is to identify the influence of the thermal treatment on the tensile behavior of materials (since for the each type of matrix one formed laminate was thermally treated and the other one was not).

In other studies, the behavior of laminates had been analyzed under tensile conditions [26, 40, 45], as well as the effect of the modification of the epoxy resin, the effect of the type of fabric used in the reinforcement of the layers, but also the influence of the variation of the number of layers of each fabric (carbon, aramid, glass) as well as the influence of changing the fibers orientation in the laminates reinforcement [46-48].

The standard tensile samples were extracted from the formed plates at one year after their formation using a high pressure water jet cutting machine fig. 2a. The tensile tests were done on an Instron machine with maximum loading capacity of $100 \mathrm{kN}$. The tests were set for a loading speed of $5 \mathrm{~mm} /$ minute and the stop condition was set at $50 \%$ drop of force or $50 \mathrm{~mm}$ displacement of grips. Al tests were video recorded (with two video cameras) in order to point out the precise moment of the failure. Also the testing segment of each sample was monitored using thermo-vision Fluke Ti400 video camera in order to identify eventual heating of samples during the tests. More than that, it was ensured the identification of each sample position (fig. 2b) into the original plate (fig. 2c) with the aim of explaining possible different behaviors of certain samples (the ones extracted from the edges of original plates or the ones affected of invisible defects such as matrix discontinuities).
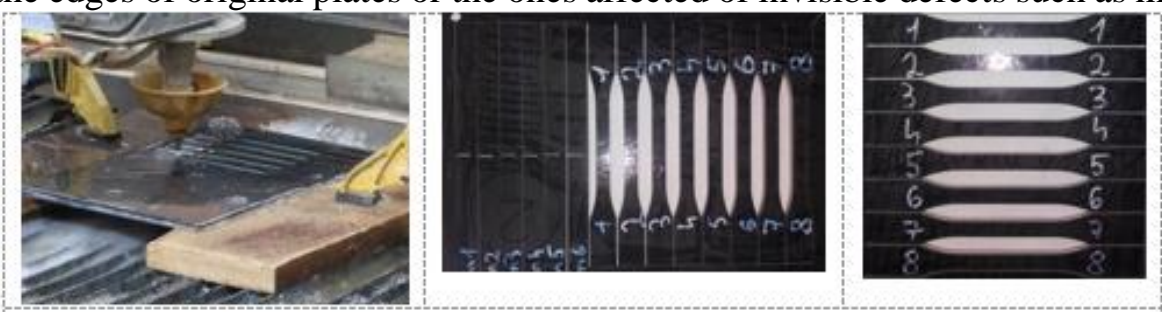

Fig. 2. Water jet cutting 2a (left). The entire material with cut samples $2 b$ (center). The tensile tests samples 2c (right)

\section{Results and discussions}

All the samples for a certain material had been tested during one day period (in fact three to four hours) to ensure, practically, the same value of the laboratory air temperature. One video camera was positioned such as to record one face of the sample while the second one was positioned such au to record one of the lateral edges of the sample. The decision to do that was made on the basis of the necessity to correlate various critical points on the loading curves with recorded moments on sample evolution but because of the low resolutions of the two cameras the only success was to extract images 
of the samples at the very moment they failed. The thermos vision camera was laced such as to record both a face and an edge.

In order to realize a the best analysis of the results all the results were statistically analyzed end for each material the averaged curve was realized using three to five partial results, corresponding respectively to three to five tested samples their numerical marks being mentioned on the general curves graphs.

On the right corner of general graphs there are presented two images (a front one and a lateral one) of the samples with the lowest response on the respective series. On another hand, on the graphs presenting the averaged curves there are presented, together with front and lateral images, the images of the highest value of temperature reached by a sample selected - by statistical means - as part as averaging process.

In the case of $C$ matrix materials - fig. 3. - it is easily to notice that in the case of natural polymerized materials the dispersion data of individual results is larger than the dispersion data of thermally treated materials but the differences are not too significant. It is interesting that the samples with the lowest response for both series are the ones numbered with 8 viz. the ones at the edge of composite plate and because of that perhaps their structure was affected by the high pressure water jet tacking into account the fact the penetration of the plate by the water jet started with these samples. After the 8 samples are detached the composite plate rigidity is lowered and it is less probable to affect the next future samples.

It has to be said that regarding the samples with approximately same behavior the sample numbered as 5 was the one having the highest increase of temperature value for both natural polymerized and thermally treated materials. The difference between the highest (sample 5) and lowest (sample 6) values of temperatures for natural polymerized composite material is of $18.64^{\circ} \mathrm{C}$ while the other two samples recorded values of temperature around the average of the extremes. On the graphs of $\mathrm{C}$ materials is observable the fact that the heating of sample 5 is extended between the two fracture points. On the graph of averaged curve for $\mathrm{CT}$ materials (thermally treated) the differences between extreme values of temperature is of $5.74^{\circ} \mathrm{C}\left(48,49^{\circ} \mathrm{C}\right.$ for sample 5 and $42.75^{\circ} \mathrm{C}$ for sample 6). In this case for the sample 1 was recorded a value of $48.47^{\circ} \mathrm{C}$ (practical the same as for sample 5) and for the last sample the recorded value was $45.09^{\circ} \mathrm{C}$.

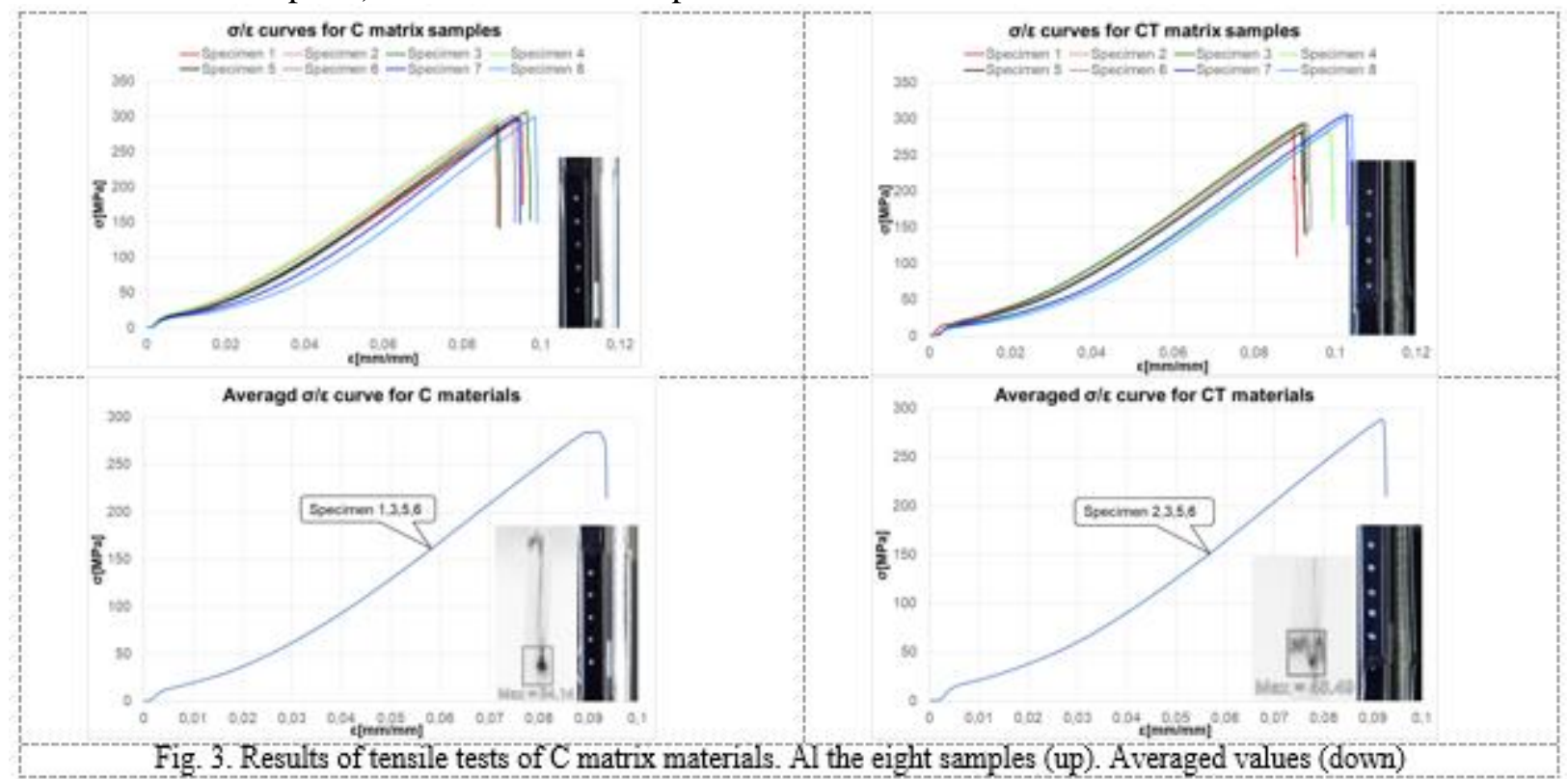

Analyzing just the thermal aspects it might be said that the thermal treatment contribute to the composite material consolidation leading to better quality interfaces. There is something else namely the fact that the CT materials (selected after statistical analysis) are failing by fracture of the external block of carbon fibers on one face of the sample while the natural polymerized materials are failing by fracture of both blocks of carbon fiber fabric reinforcement. Generally, for the $\mathrm{C}$ materials and CT materials the core of the reinforcement is not affected for the case of all averaged samples.

In fig. 4. there are presented the curves for individual samples and the pictures in the right corner corresponds to the samples with the lowest recorded tensile response. In the case of E materials, the sample number 6, and in the case of ET materials, again, the sample number 8. Regarding the poor response of the sample 6 perhaps its behavior is due to some internal defects (lack of polymer between two or more reinforcement sheets) and the fracture of the sample affected both packets of external reinforcement layers with their displacement from the core of reinforcement. The difference of heating temperature values for E materials is of $17.97^{\circ} \mathrm{C}$ (between sample 1 - and sample 8 ) the other two values being around the 


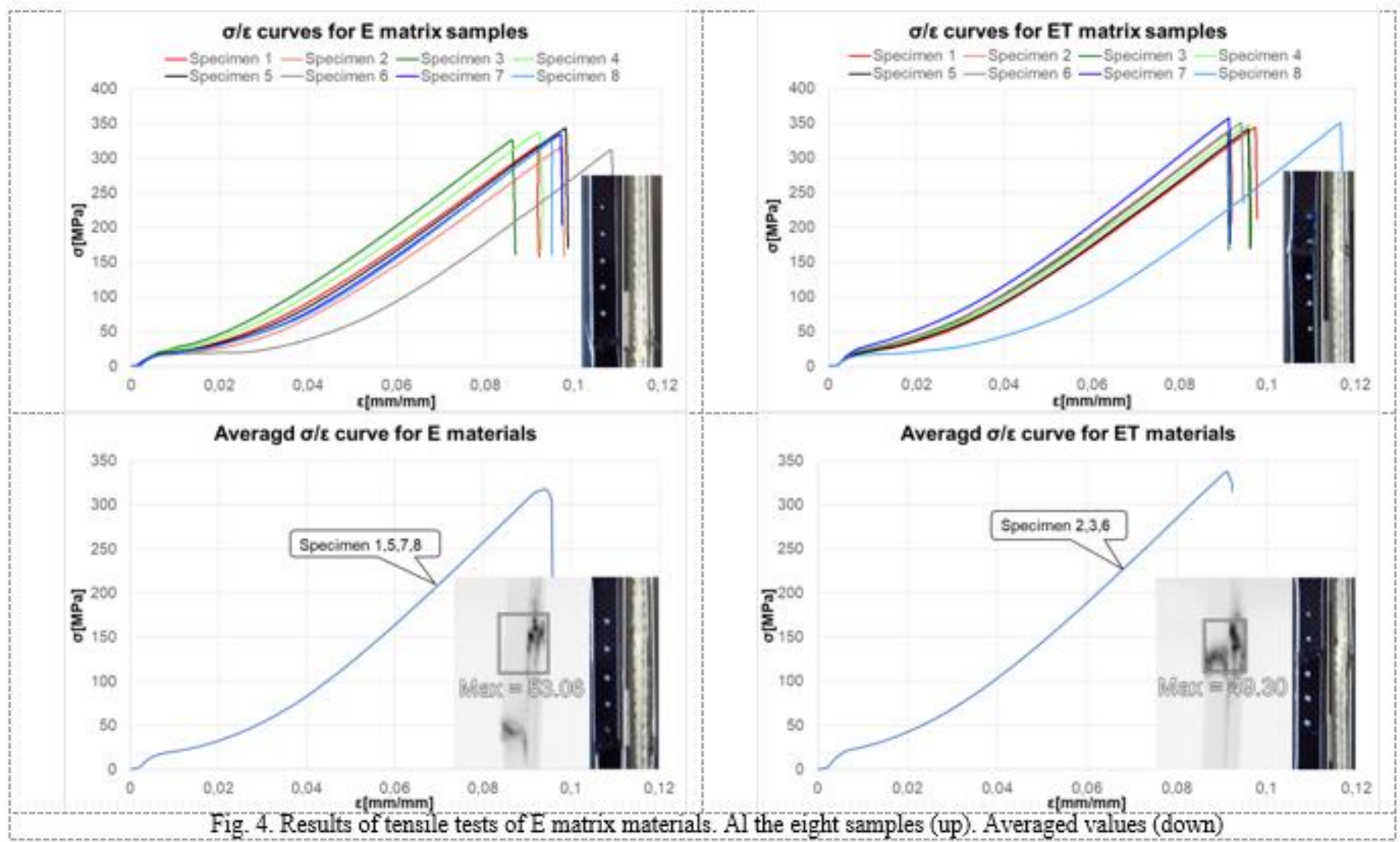

average of extremes. In the case of ET materials (sample 6 and sample 3, respectively) the temperature difference is of $3.31^{\circ} \mathrm{C}$ but the highest value is reached in the case of sample 4 and is of $51.68^{\circ} \mathrm{C}$. From the mechanic point of view it is easily to notice that the dispersion of sample responses is higher in the case of natural polymerized materials than the case of thermally treated material.

Regarding the $\mathrm{H}$ matrix materials, the results are shown in fig. 5. As in the case of other presented materials the dispersion

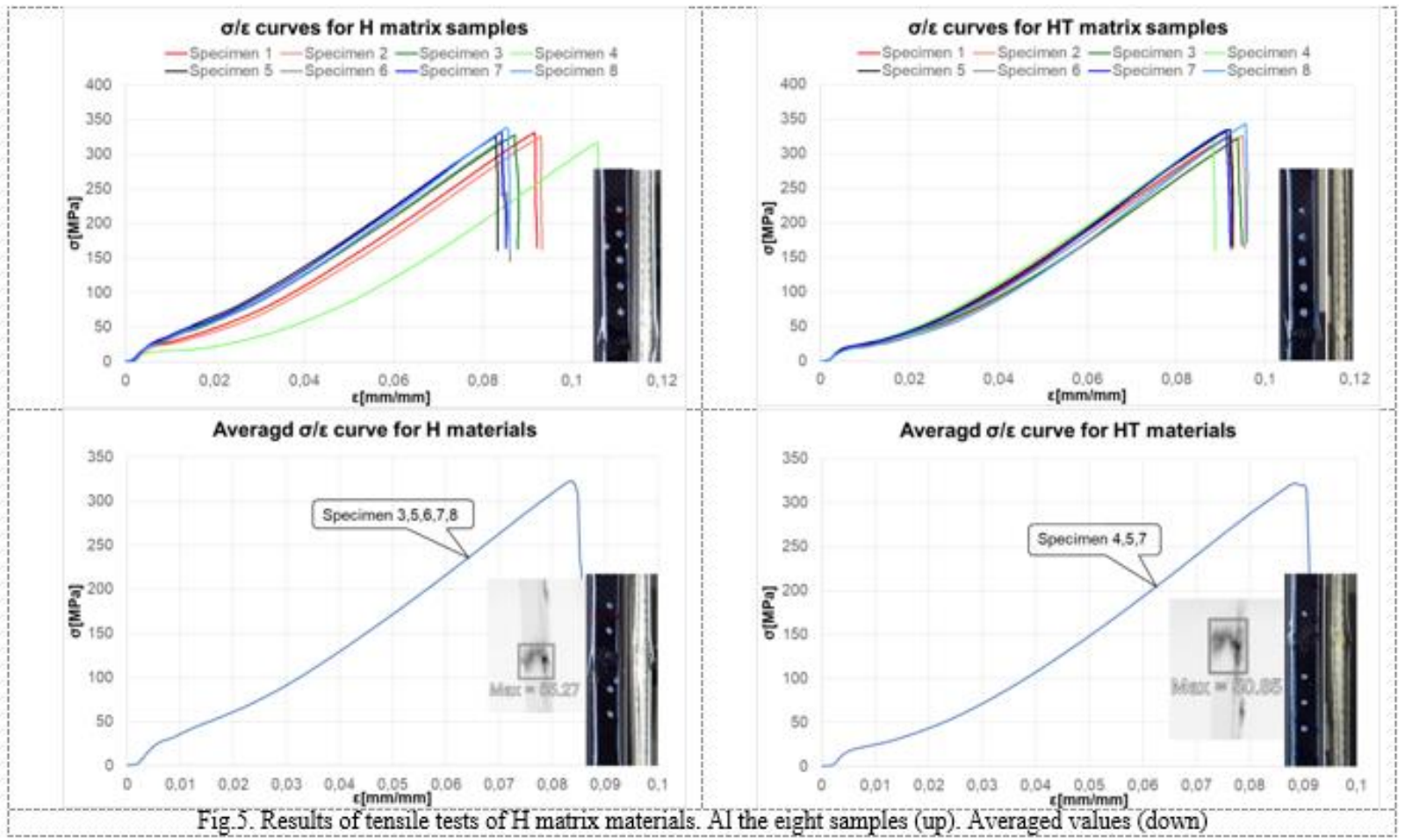


of tensile testing results are more dispersed in the case of naturally polymerized material ( $\mathrm{H}$ materials) and, also as in the already presented results, for these materials the fracture affected both blocks of external layers of reinforcement (the ones made of carbon fiber fabric $\mathrm{C} 240$ ) but in some cases (the ones there are presented as having the lowest response $-\mathrm{H}$ matrix sample number 4 and, HT matrix sample number 8 - the core of the material is also affected. The averaged curves for these materials are made over five samples in the case of $\mathrm{H}$ material and over four samples in the case of HT material. The heating effect at the break is present also and it is of highest value of $12.4^{\circ} \mathrm{C}\left(57.48^{\circ} \mathrm{C}\right.$ for sample 1 and $45.08^{\circ} \mathrm{C}$ for sample 5 and sample 6) for the $\mathrm{H}$ matrix material and is of highest value of $5.77^{\circ} \mathrm{C}$ (sample number 7 and sample number 5) for the $\mathrm{HT}$ matrix material. The low dispersion of the results denotes that in the case of $\mathrm{H}$ matrix materials the matrix-reinforcement interphase could be of better quality.

The last two materials - just because we assumed to present them alphabetically - are presented in fig. 6 . In this case it easily to notice that the dispersion of the naturally polymerized samples did not allowed an average over more than three samples. In the case of L matrix material the lowest response is, again, the one of sample number 8 while in the case of HT matrix material the lowest response was considered the one of sample number 7. For these composite materials it was noticed that the core of the reinforcement is affected by tensile tests (in both cases of naturally polymerized matrix $-\mathrm{L}$ and, thermally consolidated matrix - LT). Regarding the increase of temperature value there were recorded a difference of $8.07^{\circ} \mathrm{C}$, for the L matrix material and, of 13.02 , for the LT matrix material (which seems to be opposite from the other three materials). It has to be mentioned the fact that the highest temperature values reached during these materials testing were $62.20^{\circ} \mathrm{C}$ for E material, sample number 7 and, $65.09^{\circ} \mathrm{C}$ for ET material sample number 2.

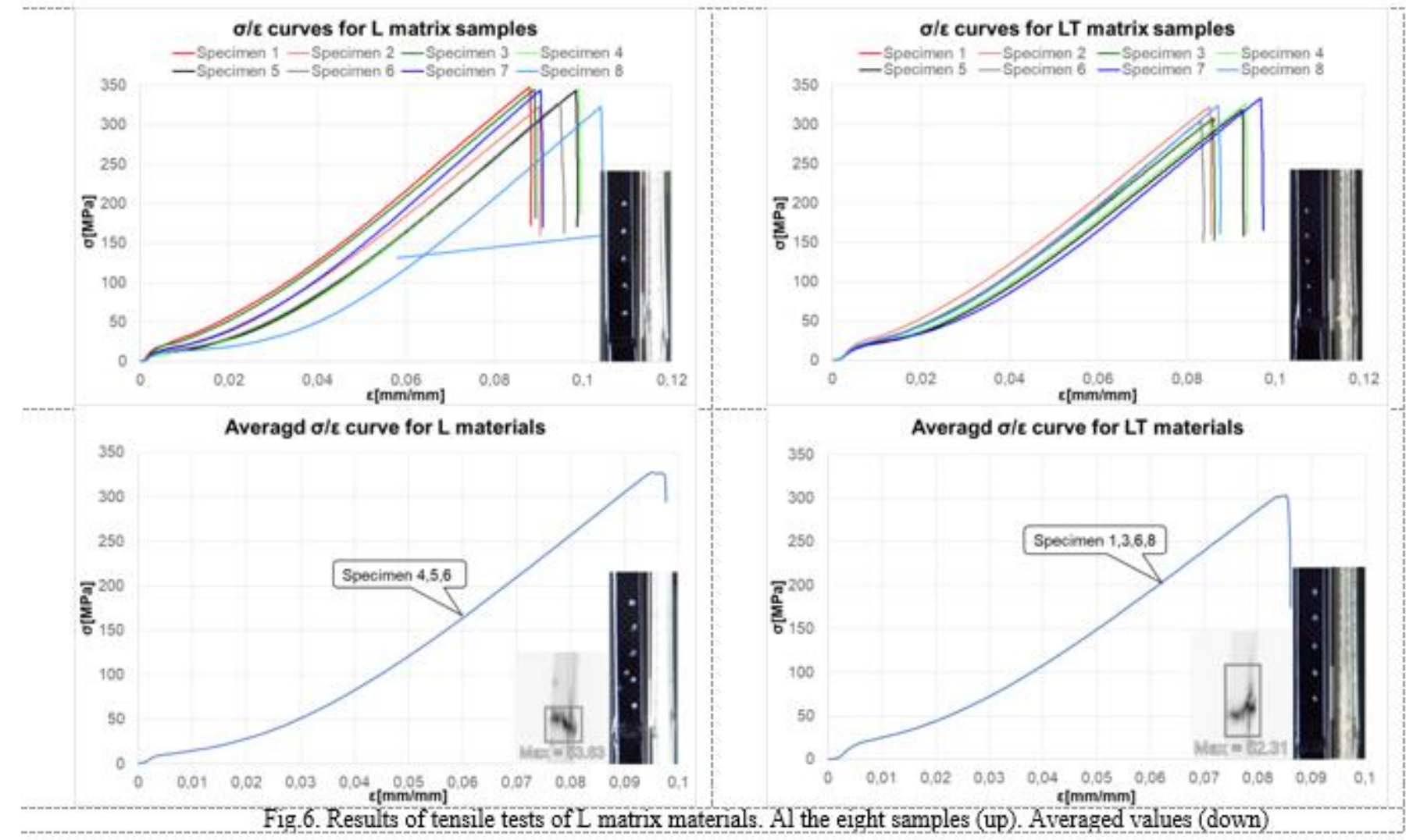

Regarding the heating of the samples at break it might be assumed that the final value of the temperature is connected both with the quality of the matrix-reinforcement interphase and with the amount of energy released when the carbon fibers are breaking. It is possible to see that the high temperature zones are corresponding mainly to the external reinforcement layers (carbon fibers ones) for all the studied materials. In Table 2 the values of temperature at break are presented for all the tested samples and these values should interpreted as mechanical effects but at this moment the values of specific heat capacity of materials are not available. On dark background are presented the temperature values at break for the samples that were used to build up the averaged curve for each material. The average temperature values had been evaluated both for the entire set of samples and just for the samples with closed mechanical responses and the values are given in Table 3. These values are corresponding not to highest temperature values but for the increase of the temperatures and they had been obtained after the initial temperature value of the sample was removed. 
Table 2

TEMPERATURE VALUE $\left[{ }^{\circ} \mathrm{C}\right]$ AT BREAK FOR EACH TESTED SAMPLE

\begin{tabular}{|c|c|c|c|c|c|r|r|r|r|}
\hline Material & Sample 1 & Sample 2 & Sample 3 & Sample 4 & & Sample 5 & Sample 6 & Sample 7 & Sample 8 \\
\hline Cmatrix & 41,89 & 42,88 & 44,41 & 46,85 & & 54,14 & 35,51 & 44,20 & 38,78 \\
\hline $\begin{array}{c}\text { CT } \\
\text { matrix }\end{array}$ & 39,40 & 48,47 & 45,09 & 36,00 & & 48,49 & 42,75 & 42,55 & 51,86 \\
\hline Ematrix & 53,06 & 51,35 & 44,04 & 43,45 & & 49,58 & 48,42 & 45,82 & 35,63 \\
\hline $\begin{array}{c}\text { ET } \\
\text { matrix }\end{array}$ & 48,56 & 49,30 & 45,99 & 51,68 & & 47,98 & 49,30 & 51,49 & 49,98 \\
\hline Hmatrix & 67,10 & 45,30 & 37,15 & 45,82 & & 45,93 & 29,23 & 37,72 & 55,27 \\
\hline $\begin{array}{c}\text { HT } \\
\text { matrix }\end{array}$ & 53,77 & 47,88 & 57,48 & 46,33 & & 45,08 & 45,08 & 50,85 & 45,17 \\
\hline L matrix & 50,62 & 46,72 & 54,34 & 53,63 & & 48,55 & 45,56 & 62,20 & 40,34 \\
\hline $\begin{array}{c}\text { LT } \\
\text { matrix }\end{array}$ & 43,35 & 65,09 & 48,61 & 54,82 & & 44,32 & 39,29 & 50,10 & 52,31 \\
\hline
\end{tabular}

The assumption that there it is possible to connect the increase in temperature value and some mechanical effects induced by tensile loading, fails when analyzing the results presented in Table 3. It is possible to notice that, generally, the average increase in temperature is slightly larger in the case of thermally consolidated materials excepting the $\mathrm{L}$ material when the average value of temperature value increase is higher for the naturally polymerized material. Also it is possible to notice that the average temperature value for $\mathrm{C}$ and $\mathrm{E}$ materials in the case of selected samples (it is about the statistic selection) is higher than in the case of naturally polymerized correspondents and it is reversed for the case of $\mathrm{H}$ and $\mathrm{L}$ materials. From previous studies it is known that $\mathrm{H}$ and L polymers (Epoxy Resin HT and Epoxy Resin L) are more brittle than the other two resins and an explanation could be found on this, meaning that micro-fractures of matrix lead to local heating of materials residing in a higher temperature at the end.

Table 3

INCREASE IN TEMPERATURE VALUES $\left[{ }^{\circ} \mathrm{C}\right]$

\begin{tabular}{|l|l|c|c|c|c|c|c|c|}
\hline & C matrix & $\begin{array}{c}\text { CT } \\
\text { matrix }\end{array}$ & Ematrix & $\begin{array}{c}\text { ET } \\
\text { matrix }\end{array}$ & Hmatrix & $\begin{array}{c}\text { HT } \\
\text { matrix }\end{array}$ & L matrix & $\begin{array}{c}\text { LT } \\
\text { matrix }\end{array}$ \\
\hline all & 16,6 & 17,33 & 19,4 & 22,3 & 18,4 & 22 & 23,24 & 22,73 \\
\hline selected & 16,99 & 19,2 & 19,02 & 21,3 & 14,06 & 20,22 & 22,25 & 18,89 \\
\hline
\end{tabular}

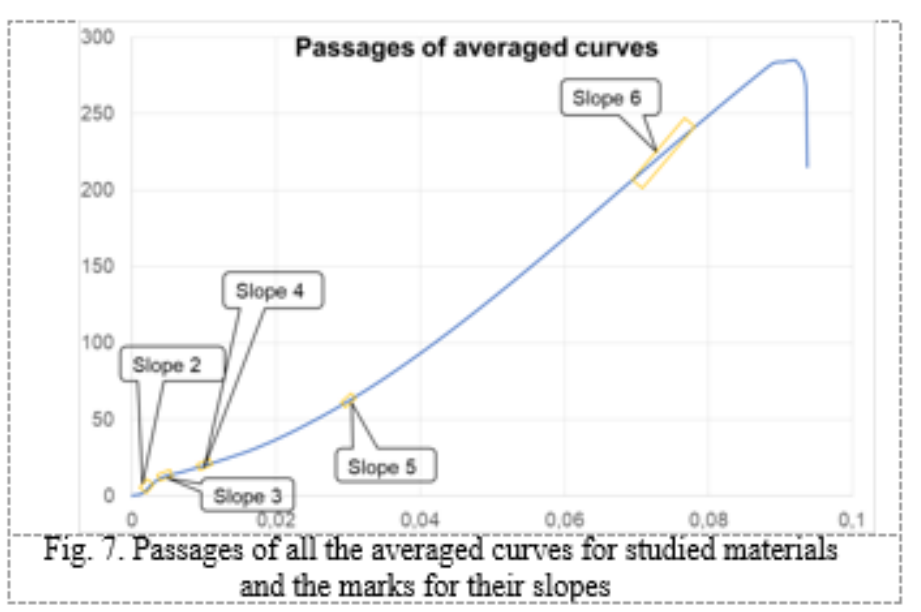

Analyzing the averaged curves in fig. 3. to fig. 6. It is possible to identify some passages of the mechanical behavior of all the samples as in fig. 7. The first passage is very short and almost horizontal and it might correspond to the clamping of the sample between pneumatic grips together with the start of the loading (this first passage is not marked in fig. 7.). The second passage corresponds to the elastic response of the material while the passages three, four and five, could correspond to failures of certain interphases like passage four that could be associated to the detachment of carbon fiber layers from the others from the core. The last passage for each material correspond to the linear response of carbon fibers fabrics out of matrix even in this case it is difficult to analyze all the mechanical loadings because the aspect of the fractures of the carbon fiber reinforcement packets at external layers look mainly as bending induced fractures and, for some samples after fracture they are rotate relatively to the core (which is maintained in loading position by the grips) signalizing that some shear efforts are appearing. In Table 4. the values of all the slopes are presented for each averaged curve and, of course, just the second MATERIALE PLASTICE 56 no. 42019 http:///www.revmaterialeplastice.ro 
could be considered elastic modulus. The elastic modulus seems to be higher for the thermally treated materials excepting the $\mathrm{H}$ matrix material. For the last three materials (E matrix, $\mathrm{H}$ matrix and L matrix) the final passages (the fifth and the sixth) are merged so the same values of correspondent slopes are presented. The final passage shows almost the same value confirming the fact that the final response of the material is a fiber response. The higher value of the elastic modulus is reached for the E matrix materials (de Epiphen resin is the less brittle one).

Table 4

VALUES OF THE SLOPES OF DIFFERENT PASSAGES ON AVERAGED CURVES [MPa]

\begin{tabular}{|l|l|l|l|l|l|l|}
\hline & Slope 1 & Slope 2 & Slope 3 & Slope 4 & Slope 5 & Slope 6 \\
\hline C matrix & 718,46 & 4947,75 & 1199,99 & 1559,19 & 2948,26 & 4038,69 \\
\hline CT matrix & 451,97 & 5802,03 & 1213,27 & 1655,41 & 2465,40 & 4077,43 \\
\hline E matrix & 460,54 & 4939,96 & 970,23 & 1811,18 & 4689,29 & 4689,29 \\
\hline ET matrix & 960,63 & 6286,14 & 1099,56 & 2019,91 & 4749,78 & 4749,78 \\
\hline H matrix & 480,79 & 7201,33 & 1818,14 & 2547,46 & 4215,95 & 4215,95 \\
\hline HT matrix & 515,38 & 6938,32 & 1262,83 & 2437,72 & 4763,94 & 4763,94 \\
\hline L matrix & 891,80 & 4042,58 & 776,80 & 2240,62 & 4613,30 & 4613,30 \\
\hline LT matrix & 479,40 & 5875,85 & 1515,10 & 2984,20 & 4622,44 & 4622,44 \\
\hline
\end{tabular}

\section{Conclusions}

Eight materials with four different epoxy resins (commercially available) were formed by to analyze the effect of consolidating the matrix on the tensile properties of materials. Each material is reinforced with 35 layers of fiber fabrics with five sheets of glass fibers at the very core, that are protected by aramid fiber fabrics (another five sheets each side) covered by mixed fabrics made of aramid fibers and carbon fibers (another five sheets each side) and at the end (as external layers) carbon fibers fabric (another five sheets each side).

Two plates of 250x340mm were formed for each matrix and one of the plates was thermally consolidated while the other one was not. The mechanical tests were developed one year after the materials formation. The sample were extracted from the original plates by using a high pressure water jet machine and the position of each sample was marked in order to associate eventual mechanical effects with the sample position.

The experimental fixture included two video cameras (one to record a face of the sample and, one to record an edge of the sample) in order to associate the mechanical tests events with the visual effects (breaking mostly). A thermos-vision camera was used to monitor the increase of temperature during tests and the results concern mostly with a release of energy (identifiable by increase of temperature value) at break.

Statistical analysis of partial results leads to the conclusion that only few of the samples can be used to characterize the materials and with these results the averaged curves $\sigma / \varepsilon$ were evaluated. Each time the samples that were used to average are mentioned on graphs together with two imagines of the fractured sample (frontal and lateral) that had presented the highest increase in temperature value. Also on the general graphs of all the samples for a given material two imagines (frontal and lateral) were presented for the sample that showed the lowest response.

The thermal measurement shows that there are differences between the consolidated materials and the one that are naturally polymerized but this values (averaged bot for the entire lot of samples or just for the similar mechanical behavior samples) are not too different and they cannot be used to interpret the mechanical results.

The mechanical behavior of materials, given by the averaged curves, presents for each material six passages. From these passages, the second corresponds to elastic response of the composite material while the sixth one represents the elastic response of the fibers. The highest value of the elastic modulus is reached for Epiphen RE4020-De40202 epoxy system (around 5Gpa) and it corresponds to the less brittle matrix (for both materials - the one consolidated by thermal treatment and the one that is naturally polymerized).

Acknowledgments: All the authors would like to acknowledge the financial support of the Project 12 P01 02421 (C11)/31.08.2012 (code SMIS 50414). The work of Vasile Bria and Adrian Cîrciumaru was supported by the project "EXPERT", Contract no. 14PFE/17.10.2018.

\section{References}

1. ALĂMOREANU, A., CONSTANTINESCU, D.M., Proiectarea plăcilor compozite laminate, Ed. Academiei Române, Bucureşti, 2005. P. 11, ISBN 973-27-1189-2.

2. A. CARAMATESCU, C.-I. MOCANU, A. MODIGA, A, Mat, Plast., 56, 2019, p. 11-17

3.*** Hexcel, Technical Fabrics Handbook, HexForce Reinforcements, U.S.A., FM 93570, 2010.

4. MARINA SCHIȚANU (BUNEA), Contribuții la studiul solicitarilor la impact ale compozitelor cu matrice epoxidica armate cu țesaturi, Universitatea Dunarea de Jos, Galaţi, Seria I 6, Nr.27, 2015.http://193.231.148.222/files/doctorat/2019/REZUMAT_TEZA_DE_DOCTORAT_-_romana-converted.pdf 
5. YAYUN LIUA, YUFENG GUOA, JUN ZHAOA, XIAODONG CHENC, HUI ZHANGA, GUOQING HUD, XIANG YUE, ZHONG ZHANG, Composites Science and Technology, 177, 2019, p. 49-56 https://doi.org/10.1016/j.compscitech.2019.04.014.

6. SANG NGUYEN, DAVID B. ANTHONY, HUI QIAN, CHUNTONG YUE, ARYAMAN SINGH, ALEXANDER BISMARCK, MILO S.P. SHAFFER, EMILE S. GREENHALGH, Composites Science and Technology, 182, 2019, p. 1-9, https://doi.org/10.1016/j.compscitech.2019.107720. 7. ARUNABHA BATABYAL, RAMESH KUMAR NAYAK, SUSHANTA TRIPATHY, Journal of Communication Engineering \& Systems, 8, no. 2, 2018, p. 66-74, ISSN: 2249-8613 (Online), ISSN: 2321-5151 (Print).

8. JOHANNES KIRN, THOMAS LORKOWSKI, HORST BAIER, International Journal of Structural Integrity, 2, No. 4, 2011, p. 458-473, DOI $10.1108 / 17579861111183948$.

9. MITRA YOONESSI, YING SHI, DANIEL A. SCHEIMAN, MARISABEL LEBRON-COLON, DEAN M. TIGELAAR, R. A. WEISS, MICHAEL A. MEADOR, ACS Nano 6, No. 9, p. 7644-7655, 2012, https://doi.org/10.1021/nn302871y

10. WENXIN WANG, DONGYAN LIU, YANJU LIU, JINSONG LENG, DEBES BHATTACHARYYA, Composites Science and Technology 106, 2015, p. 20-24

11.DANIEL WENTZEL, IGOR SEVOSTIANOV, International Journal of Engineering Science, 130, 2018, p. 129-135, https://doi. org/10.1016 /j.ijengsci.2018.05.012.

12. N. FORINTOSA, T. CZIGANY, Composites Part B, 162, 2019, p. 331-343, https://doi.org/10.1016/j.compositesb.2018.10.098.

13. PETERS, S.-T., Handbook of Composites, 2, Ed. GreenGate Publishing Services, Tonbridge, England, p. 1-1052, 1998, ISBN 0-412-54020-7.

14. REYNE, M., Technologie des composites, 2-e edition, Edition Hermes, Paris, 1995, ISBN 2-86601-455-3.

15. AKOVALI, G., UYANIK, N., Handbook of Composite Fabrication, Rapra Technology Limited, Ankara, 2001, ISBN 1-85957-263-4.

16. CHAWLA, K. K., Fibrous Materials, Cambridge University Press, Cambridge, UK, 1988, ISBN 0-521-57079-4.

17. DODU, AR., PREDA, C., BUTNARU, R., VISILEANU, E., DAN, D., CĂLIN, L., GREAVU, V., GRIGORAȘ, V., OCEANU, V., GHERMAN, ST., Manualul inginerului textilist, vol.1, Ed. AGIR, Bucureşti, 2002, ISBN 973-8466-10-5.

18. KARAHAN, M., KUȘ, A., EREN, R., International Journal of Impact Engineering, 35, 2008, p. 499-510, doi:10.1016/j.ijimpeng.2007.04.003. 19. BAKER, A., DUTTON, S., KELLY, D., Composite Materials for Aircraft Structures, American Institute of Aeronautics and Astronautics, Virginia, USA, 2004, ISBN 1-56347-540-5.

20. P. M. BHAGWAT, M. RAMACHANDRAN, PRAMOD RAICHURKAR, ICAAMM-2016, Materials Today: Proceedings, 4, 2017 , p. 7375-7380. 21. GUODONG ZHOU, WEITAO WANG, MAO PENG, Composites Science and Technology, 168, 2018, p. 312-319, https://doi. org/10.1016/j.compscitech.2018.10.01.

22. C. CAPELAA, S.E. OLIVEIRAA, J.A.M. FERREIRA, Composites Part B, 164, 2019, p. 191-197, https://doi.org/10.1016/j.compositesb. 2018.11.035.

23. LICHUN MA, YINGYING ZHU, PEIFENG FENG, GUOJUN SONG, YUDONG HUANG, HU LIU, JIAOXIA ZHANG, JINCHENG FAN, HUA HOU, ZHANHU GUO, Composites Part B, 176, 2019, p. 1-10, https://doi.org/10.1016/j.compositesb.2019.107078.

24. HAN JOO KIM, JUN HEE SONG, Improvement in the mechanical properties of carbon and aramid composites by fiber surface modification using polydopamine, Composites Part B, 160, 2019, p. 31-36, https://doi.org/10.1016/j.compositesb.2018.10.027.

25. DIMITRIOS MAMALISA, TOMAS FLANAGAN, CONCHÚR M. Ó BRÁDAIGH, Composites Part A, 110, 2018, p. 93-105, https://doi.org/10.1016/j.compositesa.2018.04.013.

26. PAUL BERE, JOLANTA B. KROLCZYK, EEMS 2017, E3S Web of Conferences 19, 2017, p.1-4, DOI: 10.1051/e3sconf/20171903018.

27. RUBAN RAJASEKAR B, ASOKAN R, SENBAGAN M, KARTHIKA R, KETHAVARAPU SIVAJYOTHI, NISHTHA SHARMA, ICOnAMMA 2017, Materials Today: Proceedings 5, 2018, p. 25323-25330.

28. DIMITRIOS MAMALIS, JAMES J. MURRAY, JAKE MCCLEMENTS, DIMITRIOS TSIKRITSIS, VASILEIOS KOUTSOS, EDWARD D. MCCARTHY, CONCHÚR M. O BRADAIGH, Composites Part B, 174, 2019, p. 1-13, https://doi.org/10.1016/j.compositesb.2019.107012.

29 ANKIT GUPTA, MOHAMMAD TALHA, Progress in Aerospace Sciences, 79, 2015, p 1-14, http://dx.doi.org/10.1016/j.paerosci.2015.07.001. 30 MAEDEH AMIRPOUR, RAJ DAS, SIMON BICKERTON, Composite Structures, 163, 2017, p. 331-341.

31. RENLIANG MA, WEIWEI LI, MOMO HUANG, MING FENG, XIAOJING LIU, Composites Science and Technology, 170, 2019 p. 128-134, https://doi.org/10.1016/j.compscitech.2018.11.047.

32. PARVEZ ALAM, DIMITRIOS MAMALIS, COLIN ROBERT, CHRISTOPHE FLOREANI, CONCHÚR M. Ó BRÁDAIGH, Composites Part B, 166, 2019, p. 555-579 https://doi.org/10.1016/j.compositesb.2019.02.016.

33. ILBEOM CHOI, DAI GIL LEE, Composites: Part A, 48, 2013, p. 1-8, http://dx.doi.org/10.1016/j.compositesa.2013.01.003.

34. NARAYAN PRASAD SAHU, DEV KUMAR KHANDE, GESH CHANDRA PATEL, PRAKASH KUMAR SEN, SHAILENDRA KUMAR BOHIDAR, IJIRST, 1, No. 7, 2014, ISSN (online): 2349-6010.

35. AJITANSHU VEDRTNAM, Composites Part B, 157, 2019, p. 305-321, https://doi.org/10.1016/j.compositesb.2018.08.062.

36. YAYUN LIU, JUN ZHAO, LINGYU ZHAO, WEIWEI LI, HUI ZHANG, XIANG YU, AND ZHONG ZHANG, ACS Appl. Mater. Interfaces, 8, 2016, p. 311-320, DOI: 10.1021/acsami.5b08766.

37. MUNTENIȚĂ, C., GRAUR, I., BOBOC, A., UNGUREANU, C., BRIA, V., The Romanian Review Precision Mechanics, Optics \& Mechatronics, 50, 2016, p. 131-135.

38. TOMO TAKEDA, TETSUO YASUOKA, HIKARU HOSHI, SUNAO SUGIMOTO, YUTAKA IWAHORI, Composites Part A, 119, 2019, p. 3037, https://doi.org/10.1016/j.compositesa.2019.01.013.

39.*** http://www.polydis.ro/wp-content/uploads/2014/08/Epiphen-4020.pdf

40.***https://shop1.r-g.de/en/art/120300

41.***https://shop1.r-g.de/en/art/105100

42.***https://shop1.r-g.de/en/art/100110

43. JUNSONG FU, MENGJIE ZHANG, LIN JIN, LIU LIU, NA LI, LEI SHANG, MING LI, LINGHAN XIAO, YUHUI AO, Applied Surface Science, 470, 2019, p. 543-554 https://doi.org/10.1016/j.apsusc.2018.11.168.

44. T. KEERTHI VASAN, S.M. SHIBI, C.K. TAMILSELVAN, Mater. Today, 2019, p. 1-7 https://doi.org/10.1016/j.matpr.2019.05.358

45. K.M. LIEW, XIN ZHAO, ANTONIO J.M. FERREIRA, Composite Structures, 93, 2011, p. 2031-2041, doi:10.1016/j.compstruct.2011.02.018. 
46.MINOO NAEBE, KAMYAR SHIRVANIMOGHADDAM, Applied Materials Today, 5, 2016, p. 223-245, http://dx.doi .org/10.1016 /j.apmt.2016.10.001

47.L.BOUAOUNE, Y. BRUNET, A. EL MOUMEN, T. KANIT, H., Composites Part B, 103, 2016, 68-73 http://dx.doi.org/10.1016/j. compositesb.2016.08.026.

48. R. RAHMAN, J.T. FOSTER, Computational Materials Science, 92, 2014, 401-415 http://dx.doi.org/10.1016/j.commatsci.2014.05.052.

49. CAPATINA A., BRIA V., BUNEA M., BIRSAN I.-G., Mat, Plast., 56, 2019, p. 370-377.

50.FEN DU, SALEH ALGHAMDI, BRIAN RIABBANS, TING TAN, Composites Part B, 172, 2019, p. 547-554, https://doi. org/10. 1016/j.compositesb.2019.05.080.

51. NURAIN HASHIMA, DAYANG LAILA ABDUL MAJIDA, EL-SADIG MAHDIB, RIZAL ZAHARIA, NOORFAIZAL YIDRIS, Composite Structures, 212, 2019, p. 476-483, doi.org/10.1016/j.compstruct.2019.01.036.

52. SABAU, E., IANCAU, H., HANCU, L., BORZAN, M., GRIGORAS, Ş., Mat. Plast., 47, 2010, p. $215-218$.

Manuscript reeived: 12.11.2019 